\title{
Investigation of selective extraction of phenolic compounds and of saccharides from Picea abies bark using organosolv
}

\section{solvents}

Franz Zeppetzauer ${ }^{1}$, Richard Nadányi ${ }^{2}$, Birgit Kamm ${ }^{3}$, Robert Putz ${ }^{4}$, Anton Lisý ${ }^{5}$ and Igor Šurina ${ }^{6,}{ }^{*}$

1 Kompetenzzentrum Holz GmbH, Altenberger Straße 69, 4040 Linz, Austria, f.zeppetzauer@wood-kplus.at

2 Slovak University of Technology in Bratislava, Faculty of Chemical and Food Technology, Institute of Natural and Synthetic Polymers,

Department of Wood, Pulp and Paper, Radlinského 9, 81237 Bratislava, Slovakia, Richard.Nadanyi@stuba.sk

3 Kompetenzzentrum Holz GmbH, Altenberger Straße 69, 4040 Linz, Austria, b.kamm@wood-kplus.at

4 Kompetenzzentrum Holz GmbH, Altenberger Straße 69, 4040 Linz, Austria, r.putz@wood-kplus.at

5 Slovak University of Technology in Bratislava, Faculty of Chemical and Food Technology, Institute of Natural and Synthetic Polymers, Department of Wood, Pulp and Paper, Radlinského 9, 81237 Bratislava, Slovakia, Anton.Lisy@stuba.sk

6 Slovak University of Technology in Bratislava, Faculty of Chemical and Food Technology, Institute of Natural and Synthetic Polymers, Department of Wood, Pulp and Paper, Radlinského 9, 81237 Bratislava, Slovakia, Igor.Surina@stuba.sk

* Correspondence: Igor Šurina, Igor.Surina@stuba.sk

\begin{abstract}
:
Enormous quantities of softwood and hardwood tree bark are generated yearly in the pulp and woodworking industry. Chemical compounds which can be found in bark extracts have important biological properties and therefore a high potential for using in the production of special formulations. In the present study, extraction of Picea abies bark with organosolv solvents was investigated to achieve a high yield of desirable compounds. For the extraction four different solvent ratios of ethanol and water were applied. The temperature range of extraction was set between 40 and $100{ }^{\circ} \mathrm{C}$ and stirring velocity of $400 \mathrm{rpm}$. Extractions were performed with a solid/liquid ratio of 1:20. Yields of phenolics, flavonoids and tannins were determined using gallic acid for total phenolic content (TPC), quercetin for total flavonoid content (TFC) and tannic acid for total tannins content (TTC) as calibration compounds. Qualitative analysis of phenolic constituents was performed after their derivatization, by gas chromatography coupled with mass spectrometry identification. The total yield of bark extract of $14.75 \mathrm{wt} . \%$ was achieved by using an ethanol/water ratio of $50 \%$ (v/v) and a temperature of $100{ }^{\circ} \mathrm{C}$. Gas chromatography results show 9 aromatic carboxylic acids as phenolic acids and quercetin and (+)-catechin as flavonoid compounds. Highest concentrations of TPC $=3.21 \mathrm{mg}$ gallic acid equivalent $/ \mathrm{g}, \mathrm{TCF}=0.62 \mathrm{mg}$ quercetin equivalent $/ \mathrm{g}$ and TTC $=0.84$ tannic acid equivalent/g were determined at the same process conditions by photometric method. This study determined the conditions for organosolv extraction of useful compounds and suggests that some of extractives, e.g., taxifolin and rhamnetin presented in the spruce bark extracts, have antiviral (SARS-CoV-2) effects. Therefore, this warrants further evaluation of the antiviral properties of spruce bark constituents.
\end{abstract}

Keywords: Phenolic compounds, organosolv extraction, spruce bark, Picea abies, GC-MS identification, Total phenolic content, Total flavonoid content, Total tannins content, Saccharide's content, antiviral properties.

\section{Introduction}

Enormous quantities of tree bark of softwood (coniferous trees) and hardwood (deciduous trees) are generated yearly in the pulp, paper, and woodworking industry. Chemical compounds which can be found in bark extracts have important biological properties and therefore a high potential for using in the production of special formulations. Biobased phenolic compounds found in spruce bark are known as value-added products with antioxidant capacity. These bioactive compounds have further antibacterial, anti-inflammatory, antiviral, antimalarial, antimutagenic, antitumor, cytotoxic, fungicidal, insecticidal, pharmacokinetic activities and properties. Therefore, using these extractive 
compounds requires adequate separation technology. Over the last few decades, the focus of research within the lignocellulosic biorefinery was set on by-product side streams in agricultural and forestry waste. It is essential for the industry and the economic growth in the future to establish "green" solutions for the refinery and processing of fossil fuels, fossil raw materials and their corresponding products [1]. In this context the valorization of process waste streams remains the objective. Especially bark is currently regarded as one of the most abundant raw materials [2]. Spruce and pine are usually used in the pulp, paper, and woodworking industry. At present, most of the bark waste will be subjected to combustion for heat or electricity. Previous works have identified different aromatic compounds such as lignans, tannins or stilbenes [3]. A comprehensive review of extractives properties and valorization of softwood bark through extraction of utilizable chemicals was carried out in the same study [3].

The extraction and purification of these desired compounds is the key tasks. Organosolv solvents are the preferred process media for biorefining lignocellulosic feedstocks, such as wood [4]. Thus, it is worthwhile to also look to valorize the bark extract by means of organosolv media. The extraction of hydrophobic structures, such as phenolics and flavonoids are the major focus because they have a great application potential due of its antioxidant capacity [5]. Pressurized or unpressurized hot-water extraction is a well-known method to obtain tannins out of bark [6]. The yield of bark extract in this process is around $17-30 \mathrm{wt} . \%$ due to the temperature range between 100 and $180^{\circ} \mathrm{C}$ using pure distilled water [6,7]. In the range of $60^{\circ} \mathrm{C}$ to $90^{\circ} \mathrm{C}$ the hot water extraction was enhanced with a dosage of $2 \mathrm{wt} . \%$ of sodium bisulfite and $0.5 \mathrm{wt}$.\% sodium carbonate to obtain $14.62 \mathrm{mmol}$ phenolic compounds per gram [8]. Due to these extraction conditions high concentrations of non-cellulose carbohydrates such as starch, pectins and hemicelluloses are quantified in the crude extracts. This improved hydrolysis of the glycosidic bonds was observed especially in the temperature range above $100^{\circ} \mathrm{C}$ (Autoclav) [9]. The total phenolic content in extracts of hot water extractions were 2.8 and $5.2 \mathrm{~g}$ per kg dry bark in the temperature range between $30^{\circ} \mathrm{C}$ and $150{ }^{\circ} \mathrm{C}$ [10]. Mozdyniewicz et al showed $14.7 \mathrm{wt} . \%$ and $16.3 \mathrm{wt} . \%$ of total solid yields in hot water extraction of Picea abies bark at $120^{\circ} \mathrm{C}$ without detailed data [11].

Bark extraction yield is enhanced using ethanol as solvent. Total extraction yields of ethanol and ethanol/water mixtures differ between $6 \mathrm{wt} . \%$ [12] and $35 \mathrm{wt} . \%$ [13]. Ethanol extracts from spruce bark total phenolic content differ between 10 $\mathrm{mg}$ [14] and $45 \mathrm{mg}$ [15] per gram of a crude extract. In previous works of Sladkova et al, $7.61 \mathrm{wt} . \%$ of total extract yield was achieved with a temperature of $100{ }^{\circ} \mathrm{C}$ and $96.6 \%$ ethanol as solvent [16]. In addition, aromatic compounds can also be extracted out of spruce bark with hexane and acetone at $90^{\circ} \mathrm{C}$ in concentrations of 0.7 and $2.8 \mathrm{mg}$ per gram dry bark (as described by Krogell et al [17]. Further experiments were done by Burcova et al, who showed 6.7 wt.\% yield after a Soxhlet extraction using $96 \%(\mathrm{v} / \mathrm{v})$ ethanol as solvent and $5.4 \mathrm{wt} . \%$ total yield using n-hexane as solvent [18]. Kreps et al achieved the isolation of phenolic compounds by the extraction with n-hexane at 60,80 and $120{ }^{\circ} \mathrm{C}$ with yields of $3.8 \mathrm{wt} \%, 4.1 \mathrm{wt} . \%$ and $5.1 \mathrm{wt} . \%$ referred to dry bark [19].

In this study, we present a systematic view on the extraction process of spruce bark and demonstrate the impact of the temperature and solvent polarity by different ethanol/water ratios. The concentration of hydrolyzed saccharide monomers compared to the amount of phenolic compound is also shown. The concentration of total phenolic content dependent on solvent polarity, temperature and time is shown to propose an improved biorefinery concept.

Bio-based phenolic compounds found in spruce bark are known as value-added products with beneficial properties. These bioactive compounds have antibacterial, anti-inflammatory, antiviral, antioxidant, antimalarial, antimutagenic, antitumor, cytotoxic, fungicidal, insecticidal, pharmacokinetic activities and properties. Here we would like to highlight the antiviral properties of spruce bark. For example, taxifolin and rhamnetin have proposed effects against coronavirus 2 (SARS-CoV-2 or COVID). In this study [29] were computationally screened over of 606 million compounds for binding at the recently solved crystal structure of the main protease (Mpro) of SARS-CoV-2. A screening of such a vast chemical space for SARS-CoV-2 Mpro inhibitors has not been reported before. After evaluation of potential off-target binding, a list of 12 purchasable compounds with binding affinity to the target protease was reported. To quickly advise ongoing therapeutic intervention for patients, were evaluated approved antiviral drugs and other protease inhibitors to provide a list of nine compounds for drug repurposing. Furthermore, were identified the natural compounds (-)-taxifolin and rhamnetin as potential inhibitors of Mpro. Rhamnetin is already commercially available in pharmacies. 


\section{Results and Discussion}

\subsection{Characterization of bark extract}

Some important properties of the bark composition are shown in Table 1.

Table 1. Bark composition (wt.\% of dm bark)

\begin{tabular}{lc} 
Constituent & Content in wt. \% \\
\hline Acid insoluble Lignin & 36.71 \\
Acid soluble Lignin & 3.57 \\
Glucose & 29.85 \\
Mannose & 9.87 \\
Arabinose & 3.33 \\
Galactose & 2.76 \\
Xylose & 4.57 \\
Ash & 2.89 \\
\hline
\end{tabular}

Spruce bark was characterized by NREL analysis dry matter ( $\mathrm{dm}$ ) [30], ash [31], carbohydrates and lignin [32] and calculated relatively to dry matter. The sum of all constituents contains $93 \mathrm{wt} . \%$. The determination of the extractives was performed twice, and the determined values were not given in the characterization of bark composition (Table 1). The results of the extractive compounds yield are shown in Table 2.

Table 2. Extraction yield of spruce bark in $\% \mathrm{w} / \mathrm{w}$ of dry bark

\begin{tabular}{ccccc}
\hline Temp $\left({ }^{\circ} \mathrm{C}\right)$ & EtOH $=0 \%$ & EtOH $=25 \%$ & EtOH $=50 \%$ & EtOH $=75 \%$ \\
\hline 40 & $5.48( \pm 0.12)$ & $7.52( \pm 0.11)$ & $10.41( \pm 0.21)$ & $10.13( \pm 0.18)$ \\
60 & $5.99( \pm 0.15)$ & $9.73( \pm 0.22)$ & $11.50( \pm 0.31)$ & $10.48( \pm 0.16)$ \\
80 & $9.49( \pm 0.27)$ & $9.66( \pm 0.19)$ & $11.67( \pm 0.28)$ & $11.84( \pm 0.13)$ \\
100 & $10.58( \pm 0.23)$ & $14.49( \pm 0.48)$ & $14.75( \pm 0.34)$ & $11.94( \pm 0.17)$ \\
\hline
\end{tabular}

Temperature and solvent ratio were selected out as parameters for the extraction. The effect of the extraction parameters on the yields of obtained soluble extracts was described as gravimetrical yields. All data are shown in Table 2. Results showed that the solvent ratio of ethanol/water of $50 \%(\mathrm{v} / \mathrm{v})$ gives the highest crude extract total yield of $14.75 \mathrm{wt}$. \%. Hot water extraction without ethanol showed a $10.58 \mathrm{wt} . \%$ yield at $100{ }^{\circ} \mathrm{C}$. Le Normand et al 2014 showed that the saccharides hydrolysis of the non-cellulose polysaccharides starts above $100^{\circ} \mathrm{C}$ and increases rapidly at $140{ }^{\circ} \mathrm{C}$ and $160^{\circ} \mathrm{C}$ [6]. That observation can be explained by low hydrolysis reactions within the carbohydrate backbone in the bark material. Crude extracts by ethanol/water extraction with ethanol content of $75 \%(\mathrm{v} / \mathrm{v})$ show constantly yields of more than 10 wt. \%. Similar yields were described by Neiva et al [20], who showed $9.48 \mathrm{wt} . \%$ with ethanol extraction and $14.88 \mathrm{wt} . \%$ by hot-water extraction. The high yield of ethanol extraction even at lower temperatures is influenced by the co-extraction of nonpolar compounds such as fatty acids or resin acids. For this a preliminary extraction with n-hexane was suggested by Valimaa et al [21]. The yield of total extracts was expressed as soluble extracts compared to inserted bark material. At $40{ }^{\circ} \mathrm{C}$ and $60^{\circ} \mathrm{C}$ the higher amount of ethanol significantly increased the extraction yield.

Ethanol is required for extracting high molecular stilbenes such as piceasides or astringines as detailed described by Gabaston et al [22]. Co et al [13] showed that ethanol and water as solvents lead to confident yields of aromatic compounds. The effect of temperature on extraction remains still a challenge. Even with low amounts of water in the solvent, a certain concentration of carbohydrates is co-extracted because of hydrolysis of the glycosidic bonds. Valimaa et al [21] used an ion exchange resin and high purity water to purify the crude extracts. In other experimental works, crude extracts were dried and dissolved in ethyl acetate as described by St. Pierre [23]. In the present study, a subsequent further treatment of the obtained extracts was not carried out due to direct quantification of saccharide monomers in the liquid phase. The results of determination of saccharides are given as the average of 3 measurements with a standard deviation $\leq 5 \%$ and are given in Table 3 . 
Table 3. Carbohydrate monomers content in $\%(\mathrm{w} / \mathrm{w})$ in the freeze-dried extracts

\begin{tabular}{ccccccccc} 
No & $\begin{array}{c}\text { Ethanol / water } \% \\
(\mathbf{v} / \mathbf{v})\end{array}$ & $\begin{array}{c}\text { Temperature } \\
\left({ }^{\circ} \mathbf{C}\right)\end{array}$ & Glu & Xyl & Man & Ara & Gal & Sum \\
\hline 1 & 0 & 40 & 0.39 & 0.14 & 0.24 & 0.15 & 0.19 & 1.11 \\
2 & 0 & 60 & 0.47 & 0.17 & 0.33 & 0.17 & 0.23 & 1.37 \\
3 & 0 & 80 & 0.49 & 0.16 & 0.34 & 0.18 & 0.24 & 1.41 \\
4 & 0 & 100 & 1.80 & 0.30 & 0.79 & 0.27 & 0.37 & 2.81 \\
5 & 25 & 40 & 0.32 & 0.13 & 0.25 & 0.17 & 0.19 & 1.06 \\
6 & 25 & 60 & 0.31 & 0.14 & 0.24 & 0.16 & 0.20 & 1.05 \\
7 & 25 & 80 & 0.38 & 0.19 & 0.29 & 0.19 & 0.23 & 1.28 \\
8 & 25 & 100 & 0.41 & 0.21 & 0.32 & 0.21 & 0.25 & 1.40 \\
9 & 50 & 40 & 0.18 & 0.11 & 0.14 & 0.12 & 0.12 & 0.67 \\
10 & 50 & 60 & 0.21 & 0.13 & 0.16 & 0.13 & 0.12 & 0.75 \\
11 & 50 & 80 & 0.23 & 0.14 & 0.19 & 0.11 & 0.14 & 0.81 \\
12 & 50 & 100 & 0.26 & 0.14 & 0.20 & 0.15 & 0.16 & 0.91 \\
13 & 75 & 40 & 0.14 & 0.10 & 0.13 & 0.07 & 0.11 & 0.55 \\
14 & 75 & 60 & 0.16 & 0.11 & 0.15 & 0.11 & 0.14 & 0.67 \\
15 & 75 & 80 & 0.17 & 0.10 & 0.16 & 0.12 & 0.13 & 0.68 \\
16 & 75 & 100 & 0.19 & 0.11 & 0.17 & 0.13 & 0.14 & 0.74 \\
\hline
\end{tabular}

Pure water extraction at $100{ }^{\circ} \mathrm{C}$ shows the highest content of carbohydrate monomers. In all obtained extracts, glucose is the predominant saccharide detected in the samples showing concentrations between $0.14 \mathrm{wt}$. \% and $1.08 \mathrm{wt}$. \% (Table 3). Mannose was also detected as the most abundant saccharide in softwood hemicelluloses till concentrations of 0.79 wt. \%. Here are several effects to consider. The gap of saccharide concentrations especially in the hot-water extractions between 80 and $100{ }^{\circ} \mathrm{C}$ is probably due to hydrolysis reactions of hemicellulose and starch layers within the bark material. In this temperature range, the hemicellulosic fraction is easily hydrolyzed due to its amorphous structure and exposition to the polar solvent. Pectins and higher molecular non-cellulosic polysaccharides are more stable and were quantified at larger concentrations using extraction temperatures of 140 and $160{ }^{\circ} \mathrm{C}$ as reported by Le Normand et al [6]. In our described extraction experiments, we did not use such high temperatures to avoid an exceed amount of carbohydrates in the crude extracts. 


\subsection{Characterization of total content of phenolics, flavonoids and tannins}

Total phenolic content is measured as gallic acid equivalent (GAE). Total flavonoid content is determined as quercetin equivalents (QE). Total tannins content is determined as tannic acid (TA). All experimental results were determined as the average of 2 measurements and are shown in Table 4.

Table 4. Concentrations of total phenolic content, total flavonoid content, and total tannins content

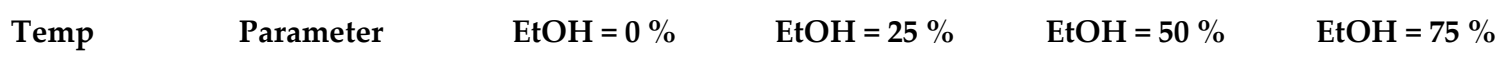

$\left({ }^{\circ} \mathrm{C}\right)$

$(\mathrm{v} / \mathrm{v})$

$(\mathrm{v} / \mathrm{v})$

$(\mathrm{v} / \mathrm{v})$

$(\mathrm{v} / \mathrm{v})$

\begin{tabular}{cccccc}
\hline \multirow{2}{*}{40} & $\mathrm{TPC}^{*}$ & $0.13( \pm 0.02)$ & $0.51( \pm 0.04)$ & $1.28( \pm 0.08)$ & $1.45( \pm 0.10)$ \\
& $\mathrm{TFC}^{*}$ & $<0.01$ & $<0.01$ & $0.24( \pm 0.03)$ & $0.22( \pm 0.04)$ \\
& $\mathrm{TTC}^{* * *}$ & $<0.01$ & $<0.01$ & $0.18( \pm 0.02)$ & $0.24( \pm 0.03)$ \\
\hline \multirow{2}{*}{60} & $\mathrm{TPC}^{*}$ & $0.1( \pm 0.01)$ & $0.66( \pm 0.05)$ & $2.19( \pm 0.17)$ & $1.82( \pm 0.14)$ \\
& $\mathrm{TFC}^{* *}$ & $<0.01$ & $<0.01$ & $0.28( \pm 0.03)$ & $0.35( \pm 0.04)$ \\
& $\mathrm{TTC}^{* * *}$ & $<0.01$ & $0.03( \pm 0.01)$ & $0.34( \pm 0.03)$ & $0.41( \pm 0.05)$ \\
\hline \multirow{2}{*}{80} & $\mathrm{TPC}^{* *}$ & $0.17( \pm 0.02)$ & $0.91( \pm 0.07)$ & $2.76( \pm 0.19)$ & $2.72( \pm 0.17)$ \\
& $\mathrm{TFC}^{* *}$ & $<0.01$ & $0.12( \pm 0.02)$ & $0.51( \pm 0.4)$ & $0.53( \pm 0.05)$ \\
& $\mathrm{TTC}^{* * *}$ & $0.09( \pm 0.01)$ & $0.14( \pm 0.01)$ & $0.39( \pm 0.03)$ & $0.64( \pm 0.05)$ \\
\hline \multirow{2}{*}{100} & $\mathrm{TPC}^{*}$ & $0.31( \pm 0.02)$ & $1.02( \pm 0.08)$ & $3.21( \pm 0.22)$ & $3.08( \pm 0.19)$ \\
& $\mathrm{TFC}^{* *}$ & $0.11( \pm 0.01)$ & $0.15( \pm 0.01)$ & $0.62( \pm 0.04)$ & $0.57( \pm 0.06)$ \\
& $\mathrm{TTC}^{* * *}$ & $0.19( \pm 0.02)$ & $0.26( \pm 0.02)$ & $0.84( \pm 0.06)$ & $0.92( \pm 0.08)$ \\
\hline
\end{tabular}

* TPC - total phenolic content, calibration standard - gallic acid (GAE), expressed as mg of GAE on g of dry bark,

** TFC - total flavonoids content, calibration standard - quercetin (QE), expressed as mg of QE on g of dry bark.

*** TTC - total tannins content, calibration standard - tannic acid (TA), expressed as mg of TA on g of dry bark.

The data obtained show that concentrations of total phenolic content and total flavonoid content are dependent on the ethanol/water ratio in the solvent. Without addition of ethanol, phenolic contents are between 0.13 and $0.31 \mathrm{~g}$ per gram of dry bark. Significantly higher concentrations of phenolic and flavonoid compounds were determined in the extracts of 50 and $75 \%$ ethanol/water ratio. By increasing the temperature, the concentrations of the target compounds enriched in the crude extracts. This may be contrary to the results of Le Normand et al [9]. In this previous study hot-water extractions were used to isolate condensed tannins from spruce bark. The disadvantage of pure water extractions with respect to biorefinery processing is the required high temperature above $100{ }^{\circ} \mathrm{C}$ and the corresponding impurification of the crude extracts by pectins and hemicelluloses. Ghitescu et al showed in their previous works that $50 \%$ and $70 \%$ ethanol are required to obtain high concentrations of phenolic compounds [12]. Sladkova et al carried out the extraction experiments with pure $96 \%$ ethanol at $100{ }^{\circ} \mathrm{C}$ and proposed this as the optimum process [16]. Legault et al described that increasing ethanol content will lead to higher total yields of bark residuals [24]. Therefore, most promising results were achieved using $50 \mathrm{wt} . \%$ and $75 \mathrm{wt} . \%$ ethanol for the quantification of bioactive aromatic compounds. 


\subsection{GC-MS characterization of bark extract}

One of the key tasks in bark extraction and purification is the identification of the target compounds. For this, GC-MS was used for compound profiling of the crude extract. Through silylation all types of hydrophilic and lipophilic extracted compounds are volatile and identified from mass spectra. In the present study, BSTFA was used in excess to enhance a complete silylation of the phenolic compounds. The GC oven program as well as detection and injection conditions were used compared to previous works on phenolic compounds as described by Proestos et al [25] and Zhong et al [26]. The Total Ion Current (TIC) chromatogram of the experiment (ethanol/water $=50: 50$, temperature $=$ $100^{\circ} \mathrm{C}$ ) is shown below as a representative example of our study (Figure 1). All phenolic compounds were identified as trimethylsilyl (TMS) derivatives and listed in table 5.

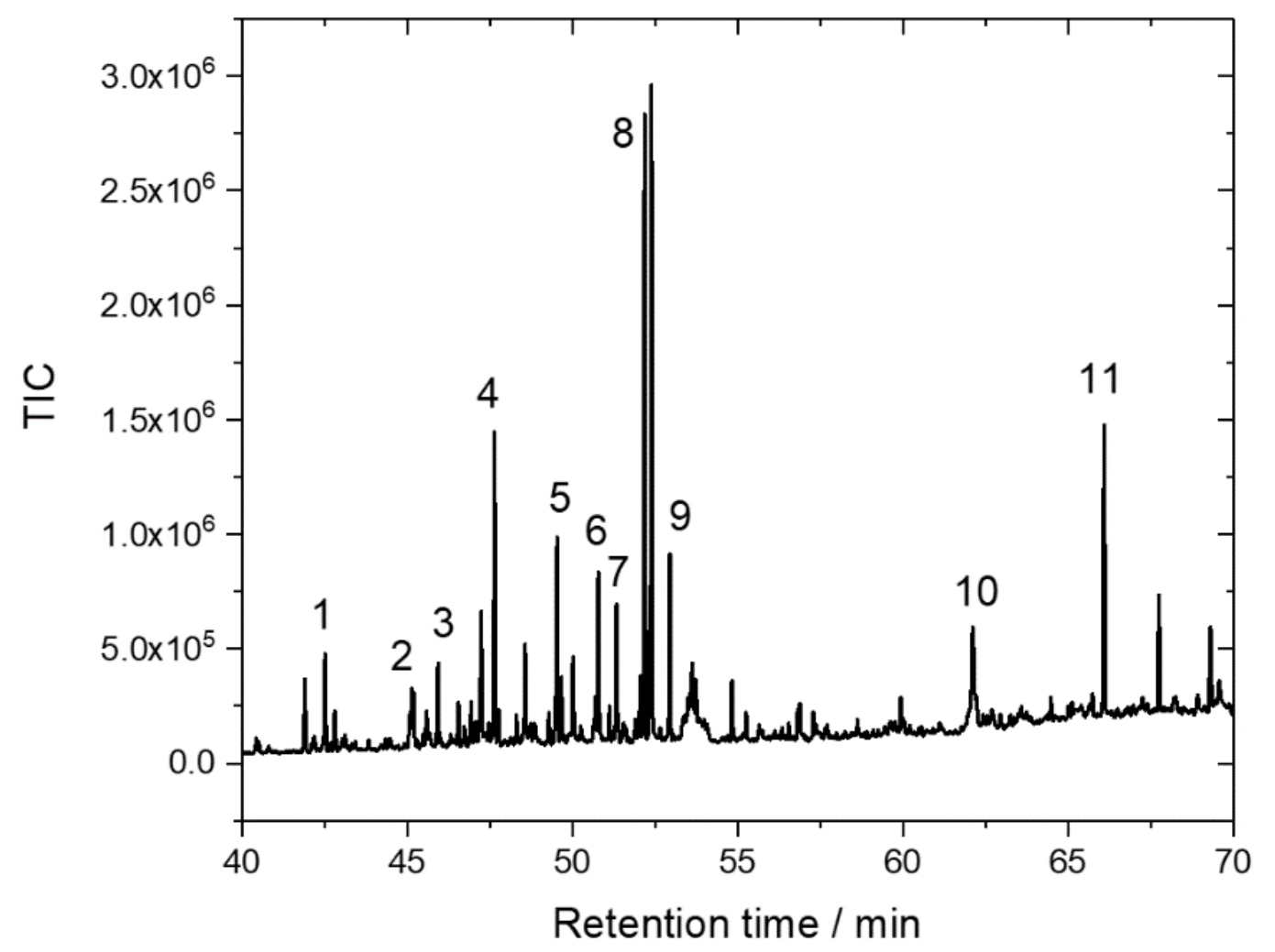

Figure 1. GC-MS analysis of phenolic compounds

( 1 = o-Hydroxybenzoic acid, $2=$ Ferulic acid, $3=$ Syringaldehyde, $4=$ Vanillic acid, $5=$ p-Hydroxybenzoic acid, $6=$ Protocatechoic acid, 7 = p-Coumaric acid, $8=$ Gallic acid, $9=$ Cinnamic acid, $10=$ Quercetine, $11=(+)$-Catechine $)$ 
Table 5: Phenolic compounds identified as trimethylsilyl derivatives

\begin{tabular}{ccll} 
N. & Rt $^{*}(\mathbf{m i n})$ & Compound & Target ions $(\mathbf{m} / \mathbf{z})$ \\
\hline 1 & 42.51 & o-Hydroxybenzoic acid & $267,73,223$ \\
2 & 45.08 & Ferulic acid & $338,73,323$ \\
3 & 45.97 & Syringaldehyde & $224,239,254$ \\
4 & 47.64 & Vanillic acid & $73,267,297$ \\
5 & 49.52 & p-Hydroxybenzoic acid & $267,73,223$ \\
6 & 50.79 & Protocatechoic acid & $73,193,370$ \\
7 & 51.42 & p-Coumaric acid & $73,219,293$ \\
8 & 52.20 & Gallic acid & $73,281,458$ \\
9 & 52.93 & Cinnamic acid & $205,131,161$ \\
10 & 62.04 & Quercetine & $73,147,193$ \\
11 & 66.15 & (+) - Catechine & $368,73,355$ \\
\hline
\end{tabular}

${ }^{*} \mathrm{Rt}=$ Retention time

As predominant phenolic compounds, aromatic carboxylic acids showed good resolution of the peaks and revealed an identification of $>90 \mathrm{wt}$. \% similarity in the mass spectra library. In most of the mass spectra the base peak of the histograms was $\mathrm{m} / \mathrm{z}=73$ due to the trimethylsilyl substituent. This was reported by Rohloff et al [27]. Especially ferulic acid, o-hydroxybenzoic acid and gallic acid are typical phenolic compounds of Picea abies. The GC-MS data obtained show a variation of aromatic compounds with different substituents only in the extraction experiments using water/ethanol $=50: 50$. Whereas experiments with ethanol/water ratio of $25 \%(\mathrm{v} / \mathrm{v})$ and without ethanol predominantly showed hydroxyl carboxylic acids and saccharide monomers. By ethanol/water ratio of $75 \%$ (v/v), more lipophilic compounds, such as fatty acids and resin acids, were detected in the extracts. Lazar et al [14] did the extraction of Picea abies bark with ethanol/water ratio of $70 \%(\mathrm{v} / \mathrm{v})$ and identified aromatic carboxylic acids as predominant compounds by HPLC-UV. As a possible explanation, no lipophilic pre-extraction of the bark material was previously conducted. Especially in the case of the ethanol/water ratio of $75 \%(\mathrm{v} / \mathrm{v})$, the occurrence of palmitic acid, stearic acid, abietic and pimaric acid was determined by GC-MS measurements. For the processing of lignocellulosic waste in biorefineries, this is one of the promising findings. The processing should be run by use of the right polarity of the solvent to avoid on the one hand a too high degree of hydrolysis and on the other hand the impurification by lipophilic compounds such as resin or fatty acids.

\section{Materials and Methods}

\subsection{Materials and Reagents}

Spruce bark was purchased from SAPPI (Gratkorn, Austria). After drying at $90{ }^{\circ} \mathrm{C}$ the bark was milled with a cutting mill and separated using a $1 \mathrm{~mm}$ sieve. Ethanol, anhydrous pyridine, aluminium chloride, and sodium acetate were obtained from Carl Roth (Karlsruhe, Germany). Bis(trimethylsilyl)-trifluoroacetamide (BSTFA), Folin-Ciocalteu reagent, quercetin and gallic acid were purchased from Sigma (Taufkirchen, Germany). Glucose, mannose, galactose, arabinose, and xylose were provided from Alfa Aesar (Karlsruhe, Germany).

\subsection{Extraction Method}

Organosolv extraction was performed in a PARR 4560 Autoclave with a volume of $450 \mathrm{ml}$ (produced by PARR Germany Frankfurt/Main, Germany). The set-up includes the monitoring of time, temperature, pressure, heating, and stirring velocity. Extractions were conducted with a solid/liquid ratio of 1:20. In each case $5 \mathrm{~g}$ of spruce bark was examined with differently defined solvent mixtures of ethanol / water. The ethanol/water ratios were chosen with $0 \%(\mathrm{v} / \mathrm{v}), 25 \%(\mathrm{v} / \mathrm{v})$, $50 \%(\mathrm{v} / \mathrm{v})$ and $75 \%(\mathrm{v} / \mathrm{v})$, respectively. Stirring control was kept at $400 \mathrm{rpm}$. The extraction time was 2 hours for all experiments and temperature was set to $40,60,80$ and $100^{\circ} \mathrm{C}$. Every experiment was conducted twice. After extraction, the crude suspension was filtered through a funnel with porosity 3. Residual bark was dried at $90{ }^{\circ} \mathrm{C}$ for 1.5 hours and its amount determined by gravimetric analysis. 


\subsection{Determination of Extractives Yield}

The yield of extractives (YE, \%) in each experiment was determined by drying the bark samples at $105^{\circ} \mathrm{C}$ to a constant weight. The results are expressed based on the dry matter weighed before and after extraction, as shown in Equation 1:

$$
\mathrm{YE}(\%)=100 \times\left(\mathrm{mi}_{\mathrm{i}}-\mathrm{m}_{\mathrm{j}}\right) / \mathrm{m}_{\mathrm{i}},
$$

where $\mathrm{m}_{\mathrm{i}}$ is the dry mass $(\mathrm{g})$ of the bark before extraction and $\mathrm{m}_{\mathrm{j}}$ is the mass $(\mathrm{g})$ of the bark after extraction and drying.

\subsection{Determination of Chemical Composition}

Determination of ash content, acid insoluble lignin, acid soluble lignin and saccharides was done according to NREL/TP-510-42618 [32]. $300 \mathrm{mg}$ of milled bark was suspended in $3 \mathrm{ml}$ of $72 \mathrm{wt} . \%$ sulphuric acid at $30{ }^{\circ} \mathrm{C}$ in a heater bath. After storage time of 1 hour $84 \mathrm{ml}$ of distilled water was added into the sample tubes and heated at $121^{\circ} \mathrm{C}$ in an autoclave for 1 hour. After cooling down the suspension was filtered over porous crucibles. Determination of acid soluble lignin was expressed as absorbance at $215 \mathrm{~nm}$ wavelength. Acid insoluble lignin (Klason Lignin) was determined gravimetrically after drying of the crucibles at $105^{\circ} \mathrm{C}$ ( 24 hours). Concentrations of carbohydrate monomers were quantified by High Performance Anion Exchange Chromatography.

\subsection{Determination of Total Phenolics Content (TPC)}

$1 \mathrm{ml}$ of extract and $5 \mathrm{ml}$ of Folin-Ciocalteu reagent were added into a $25 \mathrm{ml}$ flask and dissolved with $0.1 \mathrm{M}$ sodium hydroxide. $10 \mathrm{ml}$ of distilled water were dosed, and prepared samples were stored for $5-8 \mathrm{~min}$ for dissolution. $5 \mathrm{ml}$ of 20 wt. $\% \mathrm{Na}_{2} \mathrm{CO}_{3}$ solution were added into the $50 \mathrm{ml}$ flask containing the sample solution and filled up with distilled water. After that, sample solutions were stored for 2 hours at room temperature with mixing every 20 minutes. Total phenolic content was determined as absorbance at $760 \mathrm{~nm}$ wavelength in polystyrene cuvettes. All UV/VIS measurements were performed twice on a Thermo Scientific Multiscan Go Spectrophotometer. $10 \mathrm{mg}$ of gallic acid was dissolved in a $50 \mathrm{ml}$ flask in distilled water and used as a calibration substance.

\subsection{Determination of Total Flavonoid Content (TFC)}

$5 \mathrm{ml}$ of extracts and $15 \mathrm{ml}$ of $96 \mathrm{wt} . \%$ ethanol was added into a $50 \mathrm{ml}$ flask. After 10 min of dissolution time, $1 \mathrm{ml}$ of aluminium (III) chloride-ethanol ratio of $10 \mathrm{w} \%(\mathrm{w} / \mathrm{v})$ and $1 \mathrm{ml}$ of $0.1 \mathrm{M}$ sodium acetate solution was added to the sample. The flask was filled up with distilled water. The sample solution was stored for 2 hours at room temperature. Total flavonoid content was determined in two parallel measurements as absorbance at $415 \mathrm{~nm}$ wavelength in polystyrene cuvettes. Quercetin was used as calibration substance using $5 \mathrm{mg}$ as standard solution with different dilutions for the calibration curve.

\subsection{Determination of Total Tannin Content (TTC)}

To $1 \mathrm{ml}$ of extract, $0.5 \mathrm{ml}$ of Folin-Ciocalteu reagent was added into a $25 \mathrm{ml}$ flask. $1 \mathrm{ml}$ of $20 \mathrm{wt}$. \% was dosed and filled up with distilled water. After 2 hours of incubation time the absorbance of the solution was measured at $760 \mathrm{~nm}$ in two parallel measurements. TTC was determined using a calibration curve obtained with tannic acid (TA). Results were expressed in milligrams of tannic acid per gram of dry bark.

\subsection{Determination of Saccharide's content}

All liquid samples were diluted 1:100 and subjected to saccharides quantification. Saccharides contained in extracts were quantified by high performance anion exchange chromatography with pulsed amperometric detection (HPAECPAD). All measurements were performed on a Dionex 5000+ (ThermoFisher Scientific, Waltham, MA) equipped with a CarboPac20 Column (particle size $=6 \mu \mathrm{m}$, pore size $\leq 10 \AA$, crosslinking $=55 \%$, ion exchange capacity $=65 \mu \mathrm{eq}$ ) and a VWD detector. $1.5 \mathrm{mM} \mathrm{NaOH}$ was used as solvent $\mathrm{A}$ and $200 \mathrm{mM} \mathrm{NaOH}$ was used as solvent $\mathrm{B}$. Flow rate was set isocratically with $0.8 \mathrm{ml} / \mathrm{min}$ using a gradient of $\mathrm{A} / \mathrm{B}=80: 20$. Quantification of saccharides was achieved by a 5-point 
calibration. Saccharide's concentrations were quantified 3 times each sample and the determined standard deviation was below $5 \%$.

\subsection{GC-MS determination of phenolic compounds}

$200 \mu \mathrm{l}$ of extract was pipetted into a $1.5 \mathrm{ml}$ GC vial and subjected to lyophilization at $-54 \mathrm{C}$ for 48 hours. $900 \mu \mathrm{l}$ of anhydrous pyridine was added to the sample and kept under $70^{\circ} \mathrm{C}$ for 1 hour. The sample was cooled down to room temperature and $100 \mu \mathrm{l}$ of BSTFA was added for derivatization and heated at $70{ }^{\circ} \mathrm{C}$ for 1 hour. After cooling down, samples were separated by gas chromatography and identified by mass spectrometry. GC-MS measurements were conducted on a Shimadzu QP2010 gas chromatograph coupled with a Shimadzu QP2020 Dual Stage Mass Spectrometer. A HP5-MS column (60 m length $\times 0.25 \mathrm{~mm}$ inner diameter $\times 0.25 \mu \mathrm{m}$ film thickness; J\&W Scientific, Folsom, CA, USA) was used. The injection port was operated under the following conditions: split injection, constant column flow: $1.2 \mathrm{~mL} / \mathrm{min}$ with helium carrier gas, purge flow: $3.0 \mathrm{~mL} / \mathrm{min}$, split ratio: 1:10, total flow: $15.2 \mathrm{~mL} / \mathrm{min}$; injector temperature: $250^{\circ} \mathrm{C}$ constant. Column temperature gradient profile: $50{ }^{\circ} \mathrm{C}(15 \mathrm{~min})$, followed by $5{ }^{\circ} \mathrm{C} \mathrm{min}-1$ to $300{ }^{\circ} \mathrm{C}(5 \mathrm{~min})$. The mass spectrometric detector was operated in EI-mode $\left(70 \mathrm{eV}\right.$ ionization energy at $\left.1.13 \times 10^{-7} \mathrm{~Pa}\right)$. Ion source temperature: $200{ }^{\circ} \mathrm{C}$, transfer line: $250{ }^{\circ} \mathrm{C}$. Data was acquired in Scan mode ranging from 45 to $500 \mathrm{~m} / \mathrm{z} .1 \mu \mathrm{L}$ aliquots were injected by an AOC 6000 Autosampler. The NIST/Wiley 2014 database was used for compound identification.

\section{Conclusions}

The use of Organosolv media is of great relevance in the context of the extraction of phenolic bioactive components in the development of lignocellulosic feedstock biorefineries. In this study the extraction of phenols (flavonoids, tannins) from the bark of Picea abies was carried out. Organosolv media (ethanol, water) not only extract polyphenols, but also saccharides. Therefore, the choice of the ethanol / water ratio and the choice of suitable extraction conditions minimize the undesired saccharide extraction. Tests with an ethanol / water ratio of $50 \%(\mathrm{v} / \mathrm{v})$ showed the highest content of phenolic components with $3.21 \mathrm{mg} / \mathrm{g}$ dry bark. In the GC-MS analysis, 9 phenols and 2 flavonoids were detected in the crude extract of the experiments with an ethanol / water ratio of $50 \%(\mathrm{v} / \mathrm{v})$. The pure water extraction at $100{ }^{\circ} \mathrm{C}$ showed the highest content of carbohydrate monomers with $2.81 \mathrm{wt}$. \% of the extract. The best conditions for the isolation of hydrophobic tree bark extracts were found at an ethanol / water ratio of $50 \%$ and a temperature of $100{ }^{\circ} \mathrm{C}(14.75 \mathrm{wt}$. \%). In our previous study [3], we report the presence of taxifolin in the spruce bark extracts. Another study [29], in which over 606 million compounds were computationally screened for binding the recently solved crystal structure of the main protease (Mpro) of SARS-CoV-2, suggested that taxifolin and rhamnetin have anti-coronavirus 2 (SARS-CoV-2 or COVID) effects. Therefore, together this warrants further evaluation of the antiviral properties of spruce bark constituents.

Author Contributions: Conceptualization, design of the work, discussion and supervision, B.K. and I.Š.; writing-original draft preparation, I.Š., B.K. and F.Z.; data curation, F.Z., R.N. and A.L.; writing-review and editing, I.Š. and B.K.; project administration, B.K., I.S. and R.P.; funding acquisition, I.Š. and R.P. All authors have read and approved the version of the manuscript submitted for publication.

Funding: This research received no external funding.

Acknowledgments: The authors would like to acknowledge the support of the Slovak Research and Development Agency (SRDA), grants APVV-14-0393 and APVV-16-0088, the Austrian Research Promotion Agency (FFG), Grant Number 844608, and the Operational program Integrated Infrastructure within the project: Demand-driven research for the sustainable and innovative food, Drive4SIFood 313011V336, co-financed by the European Regional Development Fund. Authors would like to acknowledge Aleš Ház for technical support.

Conflicts of Interest: The authors declare no conflict of interest. The funders had no role in the design of the study; in the collection, analyses, or interpretation of data; in the writing of the manuscript, or in the decision to publish the results.

Conflicts of Interest: The authors declare no conflict of interest.

Abbreviations: Ara, Arabinose; BSTFA, Bis(trimethylsilyl)-trifluoro-acetamide; dm, dry matter; EtOH, Ethanol; GAE, Gallic Acid Equivalent; Gal, Galactose; GC, Gas chromatography; Glu, Glucose; HPAEC, High Performance Anion Exchange Chromatography; Man, Mannose; MS, Mass spectrometry; NREL, National Renewable Energy Laboratory of the U.S. Department of Energy; PAD, Pulsed Amperometric Detection; QE, Quercetin Equivalent; RT, Retention time; S/L ratio, solid/liquid ratio, TFC, Total Flavonoid Content; TPC, Total Phenolic Content; TTC, Total Tannin Content; wt., weight; Xyl, Xylose. 


\section{References}

1. Kamm, B.; Gruber, P.; Kamm, M.: Biorefineries - Industrial Processes and Products. Ullmann's Encyclopedia of Industrial Chemistry. 2016, I04-I01, DOI: 10.1002/14356007.I04_I01.pub2

2. Jablonský, M; Vernarecová, M; Haz, A; Dubinyová, L.; Škulcová, A; Sládková, A.; Šurina, I. Extraction of phenolic and lipophilic compounds from spruce (Picea abies) bark using accelerated solvent extraction by ethanol. Wood Research. 2015, 60, 583-590

3. Jablonský, M.; Nosálová, J.; Sládková, A.; Haz, A.; Šurina, I.; Kreps, F.; Valka, J.; Miertuš, S.; Frecer, V.; Ondrejovič, M. Valorization of softwood bark through extraction of utilizable chemicals. A review. Biotechnology Advances. 2017, 35, 726-750, DOI: 10.1016/j.biotechadv.2017.07.007

4. Süss, R.; Kamm, B.; Arnezeder, D.; Zeilerbauer, L.; Paulik, C. Homogeneously catalyzed depolymerization of lignin from organosolv medium: characterization, optimization, and minimization of coke formation. The Canadien Journal of Chemical Engineering. 2021, Online published, https://doi.org/10.1002/cjce.24055

5. Garcia-Perez, M.; Royer, M.; Duque-Fernandeza, A.; Diouf, P.; Stevanovic, T., Pouliot, R. Antioxidant, toxicological and antiproliferative properties of Canadian polyphenolic extracts on normal and psoriatic keratinocytes. Journal of Ethnopharmacology. 2010, 132, 251-258, DOI: 10.1016/j.jep.2010.08.030.

6. Le Normand, M.; Melida, H.; Holmbom, B.; Michaelsen, T.; Inngjerdingen, M.; Bulone, V.; Paulsen, B.; Ek, M. Hot water extracts from the inner bark of Norway spruce with immunomodulating activities. Carbohydrate Polymers. 2014, 101, 699-704, DOI: 10.1016/j.carbpol.2013.09.067

7. Korpinen, R.; Kallioinen, M.; Hemming, J.; Pranovich, A.; Maenttaeri, M.; Willför, S. Comparative evaluation of various lignin determination methods on hemicellulose-rich fractions of spruce and birch obtained by pressurized hot-water extraction (PHWE) and subsequent ultrafiltration (UF). Holzforschung. 2014, 68, 971-979, https://doi.org/10.1515/hf-2013-0233

8. Kemppainen, K.; Siika-aho, M.; Pattathil, S.; Giovando, S.; Kruus, K. Spruce bark as an industrial source of condensed tannins and non-cellulosic polysaccharides. Industrial Crops and Products. 2014, 52, 158-168, https://doi.org/10.1016/j.indcrop.2013.10.009

9. Le Normand, M.; Edlund, U.; Holmbom, B.; Ek, M. Hot-water extraction and characterization of spruce bark non-cellulosic polysaccharides. Nordic Pulp E Paper Research. 2012, 27, 18-23, https://doi.org/10.3183/npprj-2012-27-01-p018-023

10. Bianchi, S.; Koch, G.; Janzon, R.; Mayer, I.; Saake, B.; Pichelin, F. Hot water extraction of Norway spruce (Picea abies [Karst]) bark: analyses of the influence of bark aging and process parameters on the extract composition. Holzforschung. 2016, 70, 619631, https://doi.org/10.1515/hf-2015-0160

11. Mozdyniewicz, D.; Herchl, R.; Böhmdorfer, S.; Potthast, A. Composition of pulp mill bark waste. Lenzinger Berichte. 2017, 93, 17, AU-ISSN 0024-0907

12. Ghitescu, R.; Volf, I.; Carausu, C.; Buhlmann, A.; Gilca, I.; Popa, V. Optimization of ultrasound-assisted extraction of polyphenols from spruce wood bark. Ultrasonics Chemistry. 2015, 22, 535-541, https://doi.org/10.1016/j.ultsonch.2014.07.013

13. Co, M.; Fagerlund, A.; Engman, L.; Sunnerheim, K.; Sjoeberg, P.; Turner, C. Extraction of Antioxidants from Spruce (Picea abies) Bark using Eco-friendly Solvents. Phytochemical Analysis. 2012, 23, 1-11, DOI: 10.1002/pca.1316

14. Lazar, L.; Talmaciu, A.; Volf, I.; Popa, V. Kinetic modelling of the ultrasound-assisted extraction of polyphenols from Picea abies bark. Ultrasonics Sonochemistry. 2016, 32, 191-197, https://doi.org/10.1016/j.ultsonch.2016.03.009

15. Jablonský, M.; Majova, V.; Strižincová, P.; Sima, J.; Jablonský, J. Investigation of total phenolic content and antioxidant activities of spruce bark extracts isolated by deep eutectic solvents. Crystals. 2020, 10, 402, 1-21, https://doi.org/10.3390/cryst10050402

16. Sládková, A.; Stopka, J.; Haz, A.; Strižincová, P.; Šurina, I.; Kreps, F. Burčová, Z.; Jablonský, M. Microwave-assisted extraction of spruce bark: statistical optimization uring box-behnken design. BioResources. 2018, 13, 8993-9004, DOI: 10.15376/biores.13.4.8993-9004

17. Krogell, J.; Holmbom, B.; Pranovich, A. Hemming, J.; Willför, S. Extraction and chemical characterization of Norway spruce inner and outer bark. Nordic Pulp E Paper Research Journal. 2012, 27, 6-17, https://doi.org/10.3183/npprj-2012-27-01-p006-017

18. Burcova, Z.; Kreps, F.; Grivnova, P.; Strizincova, P.; Haz, A.; Jablonsky, M.; Šrina, I.; Schmidt, S. Spruce bark as a source of antioxidant active substances. BioResources. 2019, 14, 5980-5987, DOI: 10.15376/biores.14.3.5980-5987

19. Kreps, F.; Burčová, Z.; Jablonský, M.; Haz, A.; Frecer, V.; Kyselka, J.; Schmidt, S.; Šurina, I.; Filip, V. Bioresource of Antioxidant and Potential Medicinal Compounds from Waste Biomass of Spruce. ACS Sustainable Chemistry E Engineering. 2017, 5, 81618170, https://doi.org/10.1021/acssuschemeng.7b01816

20. Neiva, D.; Luis, A.; Gominho, J.; Domingues, F.; Duarte, A.; Pereira, H. Bark residues valorization potential regarding antioxidant antimicrobial extracts. Wood Science and Technology. 2020, 54, 559-585, DOI: 10.1007/s00226-020-01168-3

21. Valimaa, A.; Raitanen, J.; Tienaho, J.; Sarjala, T.; Nakayama, E.; Korpinen, R.; Makinen, S.; Eklund, P.; Willför, S.; Jyske, T. Enhancement of Norway spruce bark side-streams: Modification of bioactive and protective properties of stilbenoid-rich extracts by UVA-irradiation. Industrial Crops \& Products. 2020, 145, 112150, 1-12, https://doi.org/10.1016/j.indcrop.2020.112150

22. Gabaston, J.; Richard, T.; Biais, B.; Waffo-Teguo, P.; Pedrot, E.; Jourdes, M.; Corio-Costet, M.; Merillon, J.: Stilbenes from common spruce (Picea abies) bark as natural antifungal agent against downy mildew (Plasmopara viticola). Industrial Crops $\mathcal{E}$ Products. 2017, 103, 267-273, DOI: 10.1016/j.indcrop.2017.04.009

23. St. Pierre, A.; Blondeau, D.; Bourdeau, N.; Bley, J.; Desgagne-Penix, I. Chemical Composition of Black Spruce (Picea mariana) Bark extracts and Their Potential as Natural Disinfectant. Industrial Biotechnology. 2019, 15, 219-231, DOI: 10.1089/ind.2019.0007

24. Legault, J.; Girard-Lalancette, K.; Dufour, D.; Pichette, A. Antioxidant potential of bark extracts from boreal forest conifers. Antioxidants. 2013, 2, 77-89, DOI: 10.3390/antiox2030077

25. Proestos, C.; Kapsokefalou, M.; Komaitis, M. Analysis of naturally occurring phenolic compounds in aromatic plants by RPHPLC and GC-MS after silylation. Journal of Food Quality. 2008, 31, 402-414, https://doi.org/10.1111/j.1745-4557.2008.00208.x 
26. Zhong, W.; Wang, D.; Xu, X.; Wang, B.; Luo, Q.; Senthil Kumaran, S.; Wang, Z. A gas chromatography/ mass spectrometry method for the simultaneous analysis of 50 phenols in wastewater using deconvolution technology. Chinese Science Bulletin. 2011, 56, 275-284, DOI: 10.1007/s11434-010-4266-1

27. Rohloff, J. Analysis of phenolic and cyclic compounds in plants using derivatization techniques in combination with GC MSbased metabolite profiling. Molecules. 2015, 20, 3431-3462, DOI: 10.3390/molecules20023431

28. Dai, J.; Mumper, R.J. Plant Phenolics: Extraction, Analysis and Their Antioxidant and Anticancer Properties. Molecules. 2010, 15, 7313-7353, DOI: 10.3390/molecules15107313

29. Fischer, A., Sellner, M., Neranjan, S., Smiesko, M. and Lill, M. A. (2020) 'Potential Inhibitors for Novel Coronavirus Protease Identified by Virtual Screening of 606 million Compounds', International journal of molecular sciences. MDPI, 21(10), p. 3626. DOI: 10.3390/ijms21103626.

30. Sluiter, A.; Hames, B.; Hyman, D.; Payne, C.; Ruiz, R.; Scarlata, C.; Sluiter, J.; Templeton, D.; Wolfe J. Determination of Total Solids in Biomass and Total Dissolved Solids in Liquid Process Samples. Laboratory Analytical Procedure (LAP), NREL/TP-510-42621, March 2008, https://www.nrel.gov/docs/gen/fy08/42621.pdf

31. Sluiter, A.; Hames, B.; Ruiz, R.; Scarlata, C.; Sluiter, J.; Templeton, D. Determination of Ash in Biomass. Laboratory Analytical Procedure (LAP), NREL/TP-510-42622, January 2008, https://www.nrel.gov/docs/gen/fy08/42622.pdf

32. Sluiter, A.; Hames, B.; Ruiz, R.; Scarlata, C.; Sluiter, J.; Templeton, D.; Crocker, D. Determination of Structural Carbohydrates and Lignin in Biomass. Laboratory Analytical Procedure (LAP) NREL/TP-510-42618, 2012, https://www.nrel.gov/docs/gen/fy13/42618.pdf 